\title{
25 Research Square

\section{Modified Isolated Cerebral Perfusion Technique for Prevention of Stroke With Aortic Arch Replacement}

Yasumi Maze ( $\square$ ymze.19651229@gmail.com )

Ise Red Cross Hospital

Toshiya Tokui

Ise Red Cross Hospital

Masahiko Murakami

Ise Red Cross Hospital

Teruhisa Kawaguchi

Ise Red Cross Hospital

Ryosai Inoue

Ise Red Cross Hospital

Koji Hirano

Ise Red Cross Hospital

\section{Research Article}

Keywords: aortic arch replacement, cerebral perfusion, shaggy aorta

Posted Date: March 22nd, 2021

DOI: https://doi.org/10.21203/rs.3.rs-312167/v1

License: (c) (1) This work is licensed under a Creative Commons Attribution 4.0 International License.

Read Full License 


\section{Abstract}

In aortic arch replacement, an isolated cerebral perfusion method has been reported in additional to axillary artery cannulation to prevent postoperative stroke. We have made changes to this method. In other words, we devised a method to reduce cerebral embolism by performing selective cerebral perfusion via an artificial graft anastomosed to the left common carotid artery and the left subclavian artery. This method was performed in 7 cases, and all patients were discharged alive without any neurological disorders. In the surgical procedure of the aortic arch, sufficient care must be taken in the manipulation around the brachiocephalic artery and the left subclavian artery. Our method can avoid reinsertion due to desorption of the cerebral perfusion cannula and can be expected to prevent postoperative stroke.

\section{Introduction}

Currently, the surgical results of aortic arch replacement have improved ${ }^{1}$. However, in the cases of hostile aorta, such as shaggy aorta and severe calcified aorta, it is necessary to carefully consider the surgical procedure to avoid postoperative stroke ${ }^{2}$. The effectiveness of axillary artery cannulation has been reported to prevent strokes after aortic arch replacement ${ }^{3-5}$. For aortic arch repair, we have also actively introduced axillary artery cannulation. On the other hand, there are reports that retrograde turbulence from axillary artery flow may lead to the cerebral embolism ${ }^{6,7}$. Isolated cerebral perfusion technique has been reported as a method to prevent postoperative stroke ${ }^{8-10}$. We reported a method that contributes to the reduction of postoperative stroke in aortic arch replacement by modifying the previous isolated cerebral perfusion.

\section{Methods}

This study was approved by the Institutional Review Board of Ise Red Cross Hospital and the need for informed consent was waived due to the retrospective nature of the study. All methods were performed in accordance with the relevant guidelines and regulations.

Right axillary artery was exposed beneath the subclavian artery. After a median sternotomy, arterial cannulation sites (ascending aorta, right axillary artery, femoral artery combined) were determined according to the patient's status. However, the right axillary artery was connected to the selective cerebral perfusion line, and the ascending aorta and femoral artery were connected to the systemic perfusion line. A two-stage venous cannula was inserted into the right atrium. The cardiopulmonary bypass was started from there, but first, cerebral perfusion circulation from the right axillary artery was started at $400 \mathrm{ml} / \mathrm{min}$, and it was confirmed that there were no abnormalities such as an increase in circuit pressure. After that, systemic perfusion from the ascending aorta or femoral artery was started, and total flow was obtained. By exposing the innominate vein as much as possible, the left common carotid artery can be exposed. The left common carotid artery was ligated at the bottom, cerebral perfusion cannula was inserted the left common carotid artery, and cerebral perfusion was started. After anastomosing a $9 \mathrm{~mm}$ artificial graft into the left common carotid artery, cerebral perfusion was restarted via the anastomosed artificial graft. 
This procedure on the left common carotid artery promotes exposure of the left subclavian artery. Similarly, the left subclavian artery was ligated at the bottom, and then cerebral perfusion to the subclavian artery was started via the anastomosed artificial graft. Finally, the brachiocephalic artery was clamped at the bottom. With the above, complete selective cerebral perfusion was established (Figure 1). During selective cerebral perfusion, cerebral tissue oxygenation was monitored by near-infrared spectroscopy (Edward, INVOS 5100C).

Systemic cooling to $25^{\circ} \mathrm{C}$ in pharynx was applied. The left ventricular was vented through the right superior pulmonary vein. After the distal ascending aorta was clamped, the ascending aorta was opened and cold cardioplegia was delivered directly in the coronary ostia to achieve cardiac arrest. Subsequent myocardial protection was performed by retrograde infusion. Hypothermic arrest was obtained at pharynx temperature less than $25^{\circ} \mathrm{C}$, and then the aortic arch was opened and assessed. Open distal anastomosis was performed. The four branched graft (J Shield Neo, Japan LifeLine, Tokyo, Japan) was used all patients with an elephant trunk, in addition frozen elephant trunk ( $\mathrm{J}$ graft Frozenix ${ }^{\circledR}$, Japan LifeLine, Tokyo, Japan). After the distal anastomosis, systemic perfusion was resumed through the branch of the prosthesis, and the patient was fully rewarmed to $35^{\circ} \mathrm{C}$.

After proximal anastomosis was performed, coronary artery flow resumed. The first branch of the prosthesis was anastomosed to the brachiocephalic artery. Finally, the reconstruction of the left common carotid artery and the left subclavian artery was completed by anastomosing the graft that had been anastomosed with the second and third branch of the prosthesis.

\section{Results}

This method was performed in 7 cases. Preoperative and intraoperative characteristics (Table 1) and postoperative characteristics (Table 2) are shown. The average selective cerebral perfusion time was $231.7 \pm 37.6$ minutes. They work up normally and they were extubated $7.7 \pm 4.8$ hours(mean \pm standard deviation) after the operation. All patients had no neurological disorders and were discharged from hospital. In case 6 , there was a transient disturbance of consciousness after the operation, but MRI (Magnetic Resonance Imaging) showed no evidence of stroke, and the patient was discharged without neurological symptoms.

\section{Discussion}

Regarding the means of intraoperative brain protection in aortic arch repair, many institutions perform selective antegrade cerebral perfusion in Japan, and excellent results have been reported, which has greatly contributed to the surgical results worldwide ${ }^{11-15}$. We have also adopted selective cerebral perfusion as an intraoperative brain protection strategy in aortic arch repair. Thus, brain protection by selective cerebral perfusion technique has reduced postoperative stroke. However, aortic manipulation can cause stroke due to embolism, especially intimal thickening of the aorta ${ }^{16,17}$. The effectiveness of axillary artery cannulation has been reported to prevent strokes after aortic arch repair ${ }^{3-5}$. On the other 
hand, there are reports that retrograde turbulence from axillary artery flow may lead to the cerebral embolism ${ }^{6,7}$. Therefore, it has been reported that good results were obtained by the isolated cerebral perfusion methods, especially in shaggy aorta and calcified aorta ${ }^{8-10}$. As described above, we are still searching for aortic arch repair to reduce postoperative stroke. Therefore, we made further improvements to the conventional isolated cerebral perfusion method and obtained good results. The modified isolated cerebral perfusion technique we devised, first of all, an artificial graft is anastomosed to the left common carotid artery and the left subclavian artery, and cerebral perfusion is performed via the anastomosed graft. In the previous isolated cerebral perfusion method, the cerebral perfusion cannula inserted into the left common carotid artery or the left subclavian artery may be reinserted because it is removed. But in our method, the cannula is inserted via an artificial graft so there is no removal. Therefore, it is not necessary to reinsert the cerebral perfusion cannula. In the surgical procedure of the aortic arch, care must be taken when inserting the cannula into the brachiocephalic artery and the subclavian artery ${ }^{18}$. Our method can avoid the risk of reinsertion manipulation due to the desorption of the cerebral perfusion cannula. It is thought that our method will contribute to the prevention of postoperative stroke in aortic arch replacement.

Our method has not resolved the problem of atheroembolism below the descending aorta. In the 7 cases we experienced, there was no problem in this regard, but further consideration is needed.

In the aortic arch replacement, we improved the conventional isolated cerebral perfusion method and obtained good results. The most suitable disease to benefit from this method is an aortic arch aneurysm with shaggy aorta. However, in this report, not only aortic arch aneurysm but also aortic dissection is included. Further consideration is needed.

\section{Declarations}

Author contributions

Study conception and design: Y.M., T.T. Main manuscript text writing: Y.M. Data extraction: Y.M., M.M., T.K., R.I., K.H. Results analysis: Y.M. Table and Figure preparation: Y.M. All authors reviewed the manuscript before submission.

Competing interests

The authors declare no competing interests.

\section{References}

1) Committee for Scientific Affairs, The Japanese Association for Thoracic Surgery, Shimizu H, et al. Thoracic and cardiovascular surgeries in Japan during 2017: annual report by the Japanese Association for Thoracic Surgery. Gen Thorac Cardiovasc Surg.68, 414-449(2020). 
2) Fukuda I, Daitoku K, Minakawa M, Fukuda W. Shaggy and calcified aorta: surgical implications. Gen Thorac Cardiovasc Surg. 61, 301-313(2013).

3) $\mathrm{Kim} \mathrm{JH}$, et al. Axillary artery cannulation reduces early embolic stroke and mortality after open arch repair with circulatory arrest. J Thorac Cardiovasc Surg. 159, 772-778(2020).

4) Rosinski, BF, et al. Cannulation strategies in acute type A dissection repair: A systematic axillary artery approach. J Thorac Cardiovasc Surg. 158, 647-659 (2019).

5) Etz CD, et al. Axillary cannulation significantly improves survival and neurologic outcome after atherosclerotic aneurysm repair of the aortic root and ascending aorta. Ann Thorac Surg. 86, 441447(2008).

6) Minakawa $\mathrm{M}$, et al. Hydrodynamic evaluation of axillary artery perfusion for normal and diseased aorta. Gen Thorac Cardiovasc Surg. 56, 215-221 (2008).

7) Numata $S$, et al. Blood flow analysis of the aortic arch using computational fluid dynamics. Eur $J$ Cardiothorac Surg. 49, 1578-1585(2016).

8) Shiiya N, Kunihara T, Kamikubo Y, Yasuda K. Isolation Technique for Stroke Prevention in Patients with a Mobile Atheroma. Ann Thorac Surg. 72, 1401-1402(2001).

9) Sawazaki M, Tomari S, Zaikokuji K, Imaeda Y. An improved isolation technique for shaggy brachiocephalic artery and aortic arch replacement. Gen Thorac Cardiovasc Surg. 63, 533-535(2015).

10) Kasama K, et al. Impact of Isolated Cerebral Perfusion Technique for Aortic Arch Aneurysm Repair in Elderly Patients. Ann Thorac Surg. 107, 533-538(2019).

11) Kazui T, et al. Selective cerebral perfusion during operation for aneurysm of the aortic arch: a reassessment. Ann Thorac Surg. 53, 109-114(1992).

12) Shiiya $\mathrm{N}$, et al. Surgical management of atherosclerotic aortic arch aneurysm using selective cerebral perfusion: 7-year experience in 52 patients. Eur J Cardiothorac Surg. 17, 266-271(2000).

13) Kazui T et al. Improved results of atherosclerotic arch aneurysm operations with a refined technique. J Thorac Cardiovasc Surg. 121, 491-499(2001).

14) Okita $Y$ et al. Prospective comparative study of brain protection in total aortic arch replacement: deep hypothermic circulatory arrest with retrograde cerebral perfusion or selective antegrade cerebral perfusion. Ann Thorac Surg. 72, 72-79(2001).

15) Usui A et al. Risk-adjusted and case-matched comparative study between antegrade and retrograde cerebral perfusion during aortic surgery: based on the Japan Adult Cardiovascular Surgery Database. Gen Thorac Cardiovasc Surg. 60, 132-139(2012). 
16) Ura $\mathrm{M}$, et al. Ultrasonographic demonstration of manipulation-related aortic injuries after cardiac surgery. J Am Coll Cardiol. 35, 1303-1310(2000).

17) Kim $\mathrm{J}$ et al. Clinical significance of intraluminal atheroma in patients with ascending and arch aneurysm. Ann Thorac Surg. 97, 2034-2040(2014).

18) Yamanaka K, et al. The prevalence of atherosclerotic lesions in the aortic arch. (Japanese) Gen Thorac Cardiovasc Surg.43, 432-437(1995).

\section{Tables}

\begin{tabular}{|c|c|c|c|c|c|c|c|}
\hline \multirow[b]{2}{*}{ Case } & Table 1 & \multicolumn{3}{|c|}{ Preoperative and intraoperative characteristics of each cases } & \multirow[b]{2}{*}{ Operation time (min) } & \multirow[b]{2}{*}{ CPB time (min) } & \multirow[b]{2}{*}{ SCP time $(\min )$} \\
\hline & Age Sex & aortic status & Procedure & Cannulation site & & & \\
\hline 1 & $49 \mathrm{M}$ & acute dissection & TAR, FET & $\begin{array}{l}\text { It axillary artery } \\
\text { it femoral artery }\end{array}$ & 529 & 311 & 234 \\
\hline 2 & $83 \mathrm{M}$ & arch aneurysm & TAR, FET & $\begin{array}{l}\text { It axillary artery } \\
\text { ascending aorta }\end{array}$ & 460 & 282 & 208 \\
\hline 3 & $78 \mathrm{M}$ & $\begin{array}{l}\text { ascending aneury } \mathrm{km} \\
\text { arch aneurysm }\end{array}$ & TAR, LAA resection & $\begin{array}{l}\text { It axillary artery } \\
\text { ascending aorta }\end{array}$ & 487 & 256 & 193 \\
\hline 4 & $74 \mathrm{M}$ & arch aneurysm & TAR, FET & $\begin{array}{l}\text { it axillary artery } \\
\text { ascending aorta }\end{array}$ & 426 & 251 & 242 \\
\hline 5 & $56 \mathrm{M}$ & chronic dissection & TAR, FET & $\begin{array}{l}\text { it axillary artery } \\
\text { ascending aorta }\end{array}$ & 430 & 270 & 261 \\
\hline 6 & $82 \mathrm{~F}$ & arch aneurysm & TAR, FET, LAA resection & $\begin{array}{l}\text { It axillary artery } \\
\text { ascending aorta }\end{array}$ & 495 & 265 & 221 \\
\hline 7 & $79 \mathrm{~F}$ & chronic dissection & TAR, FET, LAA resection & $\begin{array}{l}\text { It axillary artery } \\
\text { ascending aorta }\end{array}$ & 591 & 356 & 298 \\
\hline
\end{tabular}

ICU: intensive care unit TAR: total arch replacement $\quad$ FET: frozen elephant trunk $\quad$ LAA: left atrial appendage $\quad$ CPB: cardio pulmonary bypass SCP: selective cerebral perfusion 


\begin{tabular}{|c|c|c|c|c|c|}
\hline & Table 2 & Postoperative characteristics of each cases & & & \\
\hline Case & Age Sex & $\begin{array}{l}\text { postoperative mechanical } \\
\text { ventilation time (hour) }\end{array}$ & Length of ICU stay (day) & Length of hospital stay (day) & Complications \\
\hline 1 & $49 \mathrm{M}$ & 4 & 2 & 12 & \\
\hline 2 & $83 \mathrm{M}$ & 11 & 3 & 12 & POAF \\
\hline 3 & $78 \mathrm{M}$ & 7 & 3 & 16 & POAF \\
\hline 4 & $74 \mathrm{M}$ & 4 & 3 & 10 & POAF \\
\hline 5 & $56 \mathrm{M}$ & 4 & 2 & 10 & \\
\hline 6 & $82 \mathrm{~F}$ & 7 & 3 & 18 & TND \\
\hline 7 & $79 \mathrm{~F}$ & 17 & 3 & 18 & \\
\hline
\end{tabular}

\section{Figures}




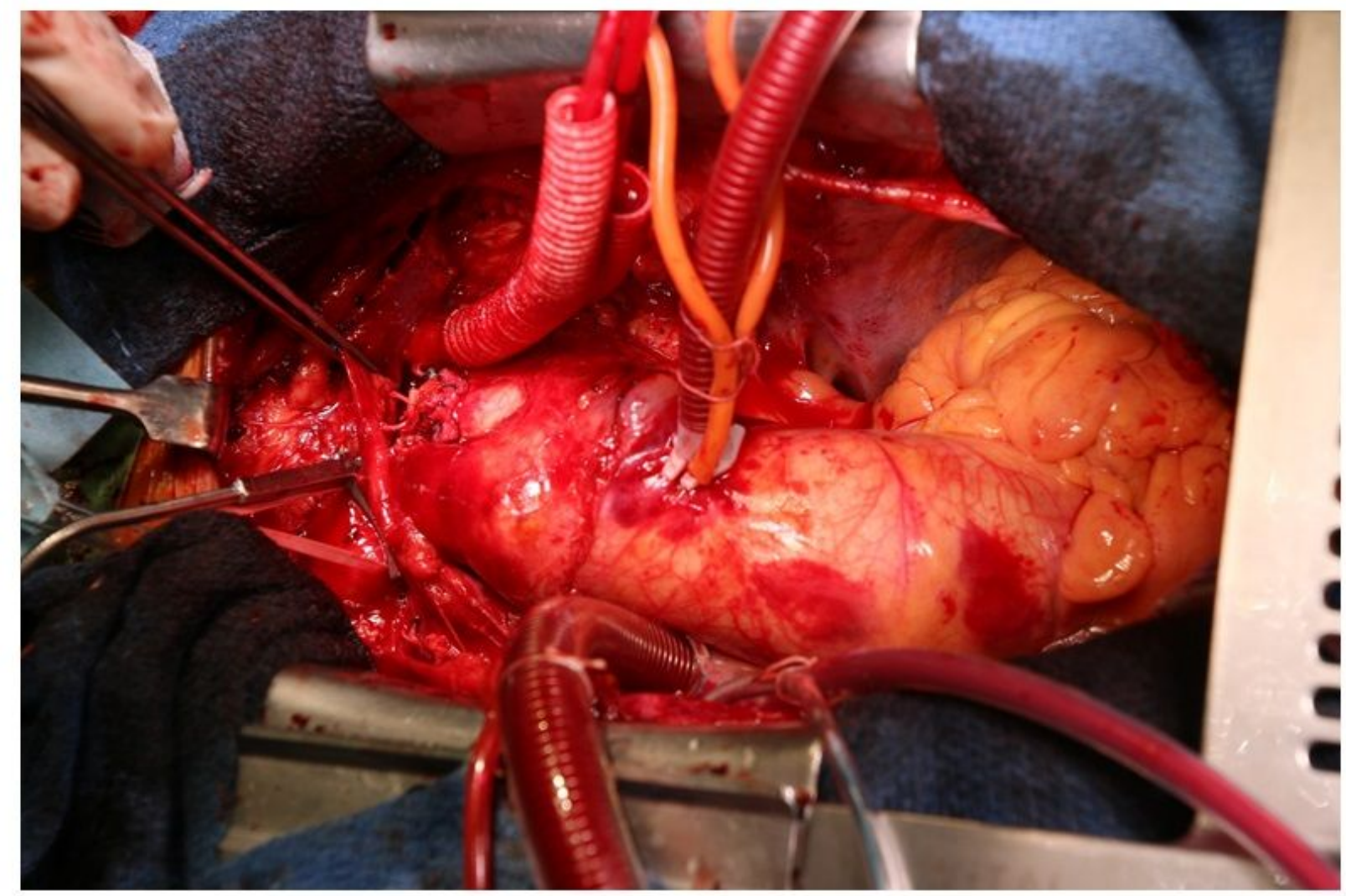

\section{Figure 1}

The right axillary artery was cannulated, cerebral perfusion was performed, and the brachiocephalic artery was clamped at the bottom. In addition, we performed cerebral perfusion via an artificial graft anastomosed to the left common carotid artery and the left subclavian artery. The left common carotid artery and the left subclavian artery were ligated at the bottom. 